\title{
Adieu Étienne
}

\section{Farewell Etienne}

\section{Le bureau de l'ANMSR}

(C) Springer-Verlag France 2010

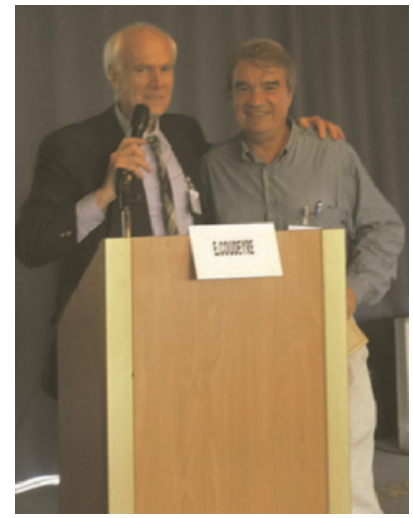

C'est avec beaucoup de tristesse que nous avons appris la disparition du Dr Étienne Jauffret, à 62 ans, le 19 juillet 2010 alors qu'il se rendait à son travail, laissant un grand vide dans les cœurs de tous ceux et celles qui ont eu la chance de croiser sa route.

Au sein du bureau de l'ANMSR, il faisait partie des « anciens », des pionniers de la première heure dans les années 1980, toujours présent et fidèle à son poste de secrétaire « perpétuel » des réunions mensuelles du bureau, comme le dénommait gentiment notre collègue Patrick Sautreuil : il rédigeait le compte rendu de chaque séance depuis plus de 15 ans, continuant à l'envoyer aux anciens membres du bureau, car pour lui c'était naturel et quasiment essentiel de conserver ce lien de l'amitié avec celles et ceux qui avaient construit notre association un peu comme une « grande famille». Il a vu se succéder depuis 20 ans tous les présidents, les trésoriers et les rédacteurs en chef de La Lettre de MPR et à ce titre, il était en quelque sorte la mémoire bienveillante de notre association.

Pour tous les participants qui assistaient à notre journée annuelle, personne ne peut oublier sa présentation du « jeu du midi » et la joie qu'il affichait à nous révéler les questions pièges qu'il nous préparait des mois à l'avance en collaboration avec un des kinésithérapeutes du centre Bullion où il travaillait. Admiratifs de son érudition dépassant largement le cadre de la médecine et de son imagination, nous attendions tous ce moment de la journée, impatients de découvrir ses questions et heureux de partager son plaisir. Car Étienne Jauffret s'amusait autant que nous à nous révéler son secret.

Au-delà de son investissement dans l'ANMSR, c'était un médecin de médecine physique et de réadaptation passionné et dévoué quotidiennement aux enfants handicapés des hôpitaux de Bullion, de Saint-Germain et de Beauvais où il passait sa vie, le jour et parfois même une partie de ses nuits sans prendre un jour de vacances. Il vivait son métier au service des enfants qu'il aimait et qui le lui rendaient bien. Ils doivent se sentir un peu perdus, aujourd'hui, sans son regard doux et patient. Vivant parmi les enfants, il en avait gardé leur candeur et leur curiosité ce qui faisait dire à notre consœur Élisette Andrianandja, trésorière de l'association pendant huit ans qu'Étienne Jauffret était un peu « notre Petit Prince ».

Dans un monde filant à toute allure, il savait donner de son temps pour encourager les enfants, écouter et rassurer leurs familles, soutenir les équipes soignantes et partager avec les équipes pédagogiques scolaires.

Il aimait aussi transmettre à nos jeunes collègues son savoir et sa passion d'aider les enfants en souffrance, et tout particulièrement les jeunes patients atteints de spinabifida, sujet qu'il maîtrisait parfaitement, ayant rédigé dans l'EMC le chapitre concernant leur prise en charge.

Étienne Jauffret était dans la vie au quotidien comme dans son métier : profondément humain, d'une gentillesse permanente et pour tous, simple et toujours discret, ne s'écoutant jamais et allant au bout de ses engagements tant professionnels qu'humains. Ainsi, depuis des années, il donnait de son temps libre un dimanche par mois à une association de bénévoles qui nettoyait la Seine ou la Marne des déchets jetés par d'autres hommes ; c'est à cette occasion qu'il s'était lié d'amitié avec une communauté de gens du voyage à qui il apportait vêtements et jouets pour les enfants. Il avait aussi d'autres passions : l'histoire de la médecine qu'il maîtrisait parfaitement. C'était aussi un tintinophile émérite ! Et un féru d'astronomie, car quand il n'avait pas la tête dans les livres, il scrutait les étoiles, laissant son esprit s'envoler vers d'autres planètes comme le Petit Prince !

Il est parti comme il a vécu, discrètement, et aujourd'hui c'est la tristesse qui nous envahit. Le bureau de l'ANMSR, anciens et membres actuels, tenait à lui rendre hommage, car c'est un peu de notre âme qui s'en va avec lui. Nous adressons aussi à ses parents, à ses deux sœurs et à son frère nos pensées et nous nous associons à leurs prières.

Sa mémoire et son image resteront présentes dans nos cœurs... Adieu « Petit Prince ». 